\title{
A Simple Cosmetic Thumb Prosthesis: A Case Report
}

\author{
Jaswinder Kaur ${ }^{1}$ \\ ${ }^{1}$ Department of Prosthodontics, Baba Jaswant Singh Dental College, \\ Hospital and Research Institute, Ludhiana, Punjab, India
}

\begin{abstract}
Address for correspondence Jaswinder Kaur, MDS, Department of Prosthodontics, Baba Jaswant Singh Dental College, Hospital and Research Institute, Chandigarh Road, Ludhiana 141010, Punjab, India (e-mail: dr.jaswinder.kaur@gmail.com).
\end{abstract}

\author{
Abstract \\ Keywords \\ - amputation \\ - acrylic \\ - maxillofacial \\ - thumb prostheses
}

Amputation of any body part, especially the thumb, can be emotionally upsetting. The degree of psychological difficulty associated with amputation generally increases with age, with all other considerations being equal. Such a situation affects a patient's mental, social, and psychological well-being. This article presents a case report of prosthetic reconstruction of an amputated thumb of a 70-year-old male through a cost-effective procedure using heat cure acrylic resin material.

\section{Introduction}

Maxillofacial prosthetics is a branch of medical and dental science that aims to, directly or indirectly, protect or restore structures that are injured or lost due to congenital or acquired means beyond the limits of a usual prosthesis, which restores the teeth and the alveolar ridges. ${ }^{1}$

In addition to function, hands also have an esthetic representation-they are a symbol, they can emphasize the beauty of the gesture or grace of the movement. ${ }^{2}$ It has been stated that the thumb with normal length digits is the most essential from the functional standpoint. ${ }^{3}$ The loss of body part, especially one as visible as the thumb, can be emotionally upsetting. Partial or complete loss of finger may be caused by accident, congenital abnormalities, or disease. Amputation is a triple threat. It involves loss of function, loss of sensation, and loss of body image.

There is little doubt that the earlier the prosthesis is applied, the better the results are in terms of functional capacity and psychological adaptation. ${ }^{4}$ Early prosthetic fitting and rapid rehabilitation enable the patient to incorporate all of his physical and emotional efforts into recovery from the earliest possible moment, rather than allowing the patient to focus only on disabilities and pain. ${ }^{5}$

\section{Case Report}

A 70-year-old male patient presented to the Department of Prosthodontics with the remaining stump of the thumb of the left hand. His chief complaint was loss of grip and unaesthetic appearance. Amputation was performed 1 year back due to an accident.

The amputated thumb was examined carefully for any signs of inflammation. It was completely healed. An informed consent was taken from the patient, and he was also informed about the limitations of the prosthesis. The patient was photographed for reference and records ( - Fig. 1).

Irreversible hydrocolloid was mixed and loaded into a plastic container. The patient was instructed to insert the thumb in a plastic container. After setting of the material, the patient was instructed to slowly remove the amputated thumb (-Fig. 2). Impression was poured in type III dental stone using a vibrator to avoid voids. Positive replica was obtained ( - Fig. 3). Similarly, impression of the thumb of the contralateral hand was made and poured with modeling wax. Wax pattern was then hollowed and adapted over the amputated model. Necessary modification was made to achieve the desired results ( - Fig. 4). During the trial stage, fit, length, and shape were verified. A nail bed was created, and the wax pattern was invested in dental plaster. Dewaxing was performed and separating media was applied. Colors were mixed with the heat cure acrylic resin to obtain a base color for both dorsal and ventral surfaces separately, and the mold was packed with the same. After curing, the prosthesis was retrieved from the mold and finished. Self-cure acrylic nail was incorporated into the nail bed already created in the wax pattern. Extrinsic coloration was used to give the
DOI https://doi.org/

10.1055/s-0038-1670729.

ISSN 2321-1482.
License terms

(ㅇ) (1) $\ominus \circledast$ 


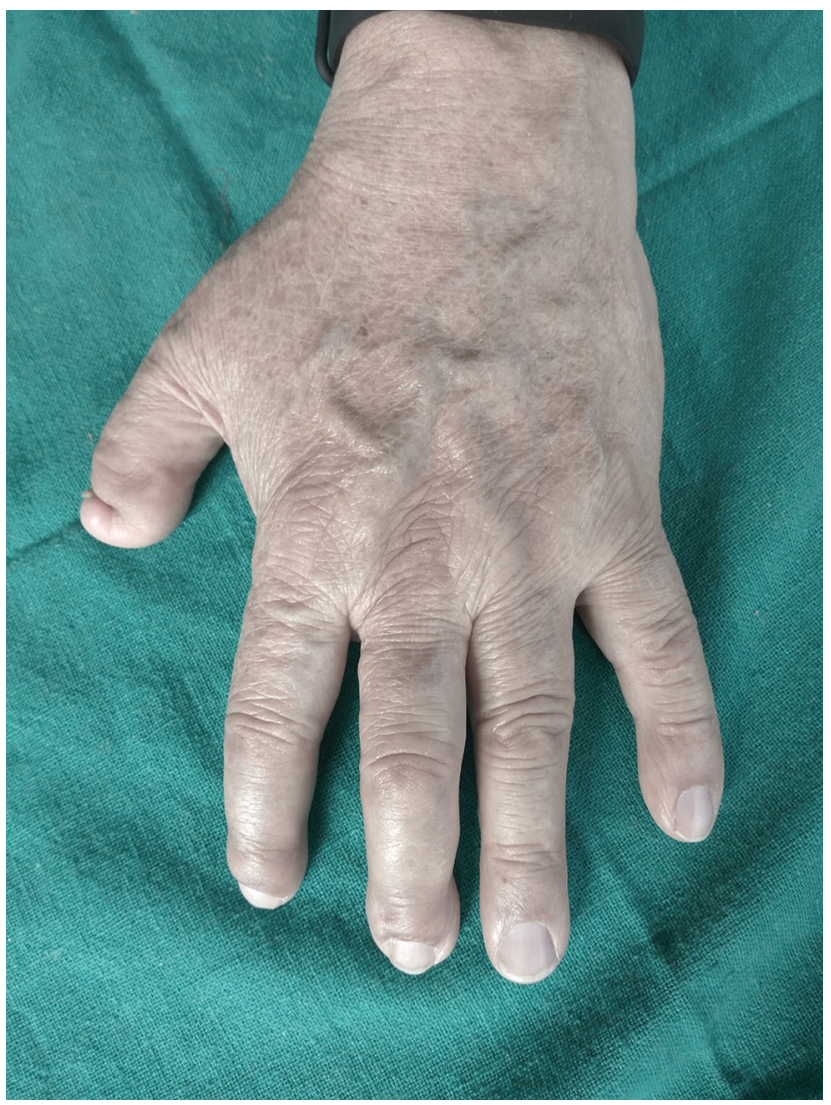

Fig. 1 Pretreatment photograph.

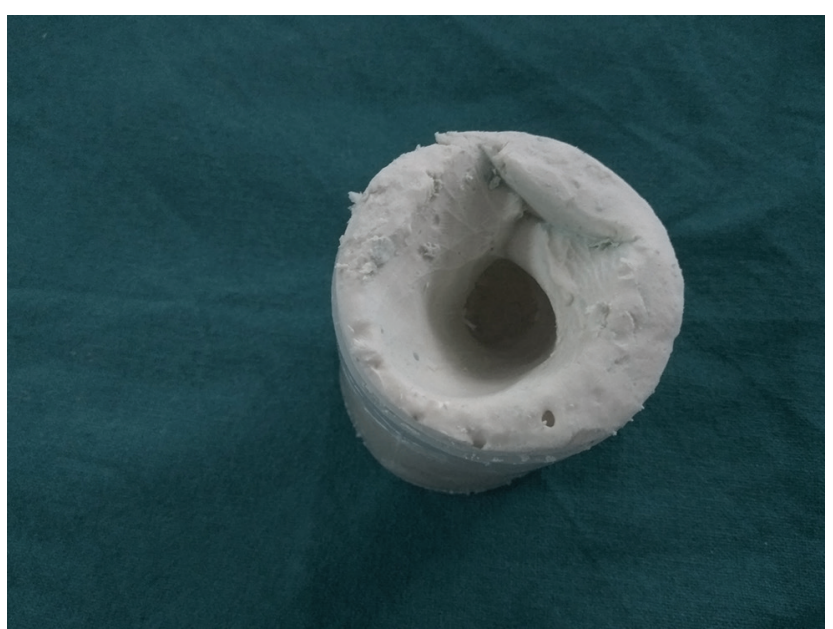

Fig. 2 Alginate impression.

prosthesis a better esthetic appearance ( - Fig. 5 ). The patient could reproduce the movement of the stump with success and without displacement of the prosthesis. The patient was educated about the use and maintenance of the prosthesis. The patient was recalled after 1 day, 1 month, and 3 months for follow-up. The patient was very satisfied with the function and esthetics of the thumb prosthesis ( - Fig. 6).

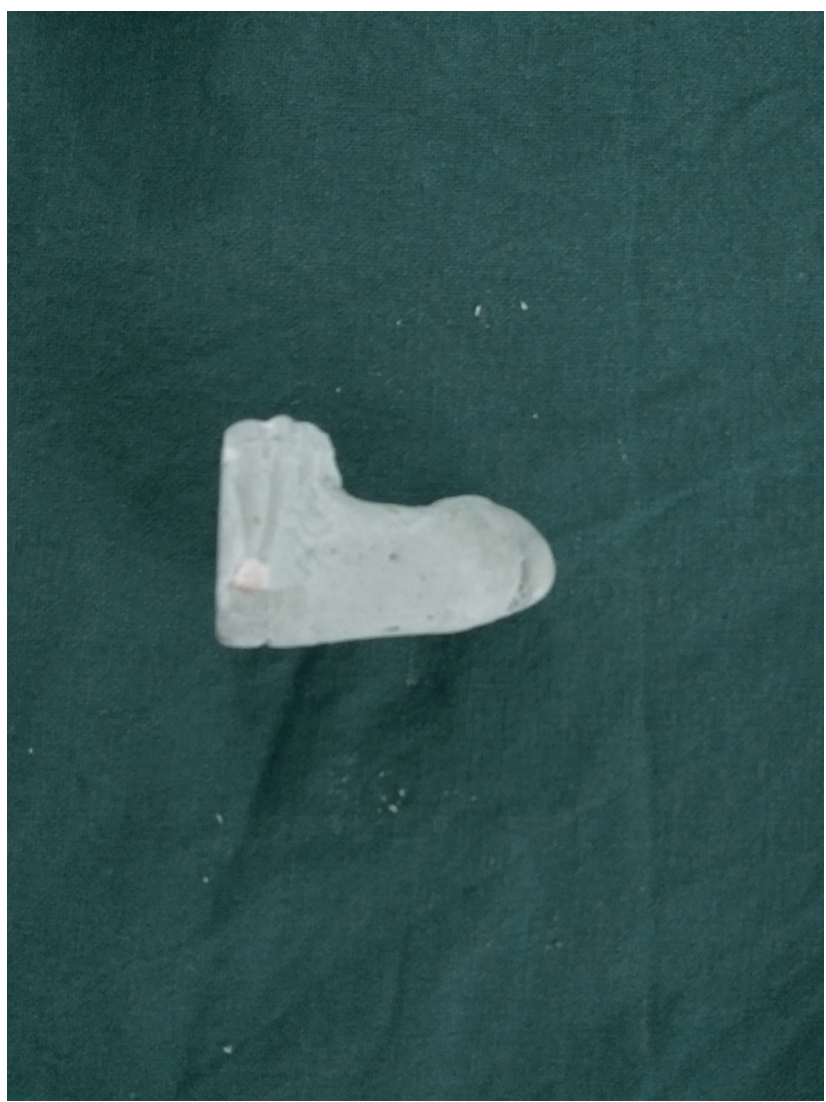

Fig. 3 Stone model of the remaining thumb stump.

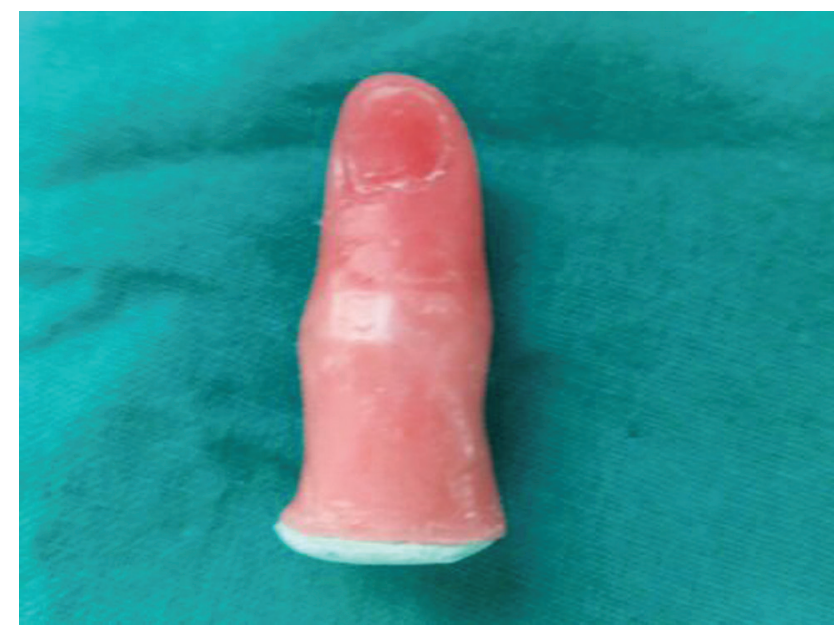

Fig. 4 Wax pattern of the prosthesis.

\section{Discussion}

Creating a prosthesis having a life-like appearance is challenging since it requires not only great artistic and technical skills but also better understanding of the patient's expectations. ${ }^{6}$ The esthetic prosthesis requires a stump in perfect condition and a well-motivated patient with realistic hopes. 


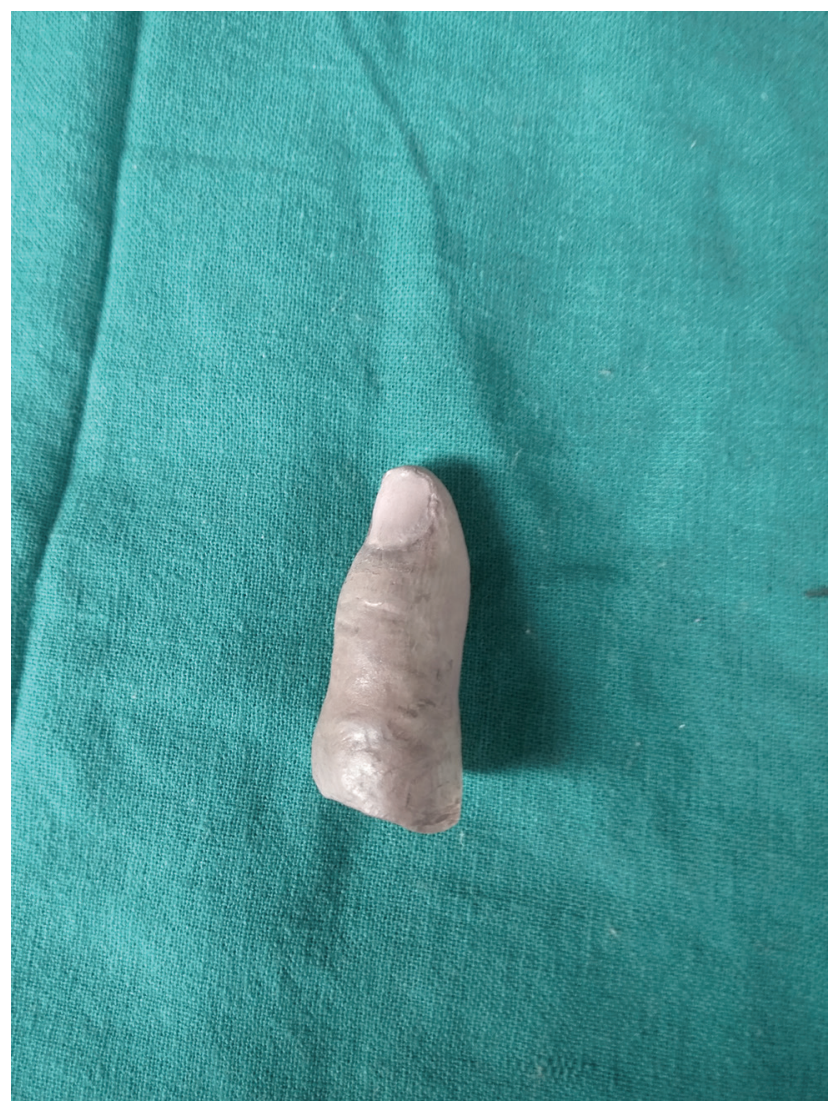

Fig. 5 Finished thumb prosthesis.

Esthetic prostheses for the hand can offer psychological, functional, and rehabilitative advantages. Pillet $^{2}$ enumerated essential requirements of an esthetic prosthesis, which are technically of high-quality, durable, strong, flexible, resistant to hardening and burning, simple, comfortable, cleansable, stain-free, and so on.

Various materials have been used to fabricate maxillofacial prostheses; silicone and acrylic resin are the most common materials used for making finger prosthesis. Although silicone has been proven to be promising material, it has shortcomings such as microbial growth, weak retention, color instability, and expensiveness. On the other side, acrylic resin materials are easily available, inexpensive, easy in intrinsic and extrinsic coloration, good in strength, color stable, and easy to repair.

Retention is the primary determinant of prosthetic restoration of any part of the body. Various retentive measures such as rings and magnets have been used to retain finger prosthesis. Due to the presence of soft tissue bulb-like extension of the amputated thumb, no extra retention was required in this case.

Prosthetic rehabilitation for patients in developing countries should exhibit functionality at a low cost, durability,

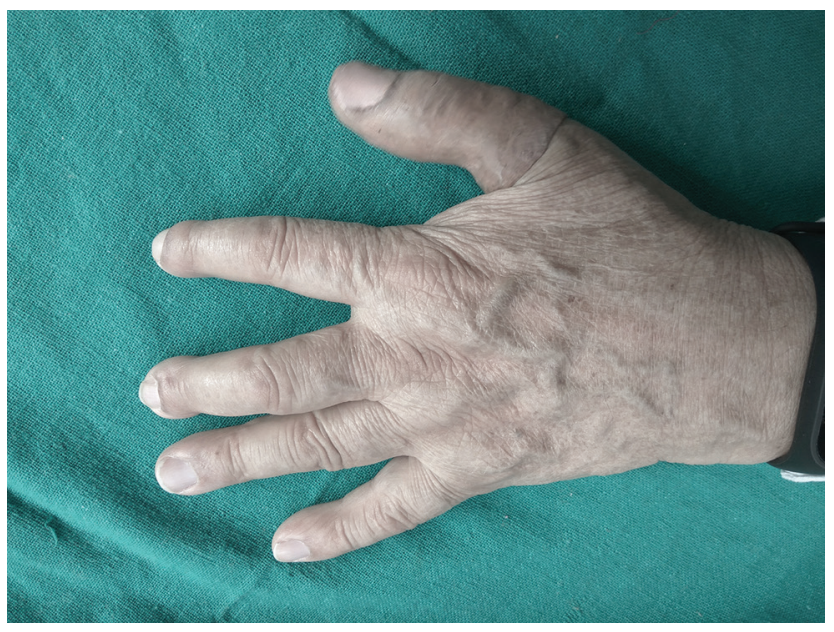

Fig. 6 Posttreatment photograph.

simplicity of repair, adaptability to local materials, and cultural acceptability. ${ }^{?}$

\section{Conclusion}

Prosthetic rehabilitation of the missing finger may not restore the function completely but it definitely helps an individual to overcome the psychological trauma and lead a healthy professional and social life. Esthetic thumb prosthesis as given in this patient offered psychological, functional, and rehabilitative advantages.

\section{Conflict of Interest}

None.

\section{References}

1 Miglani DC, Drane JB. Maxillofacial prosthesis and its role as a healing art. J Prosthet Dent 1959;9(1):159-168

2 Pillet J. Esthetic hand prostheses. J Hand Surg Am 1983;8 (5 Pt 2):778-781

3 James CH. Amputation of hand. In: Canale ST, Beaty J, eds. Campbell's Operative Orthopaedics. St. Louis, MO: CV Mosby; 2003:611-622

4 Bradway JK, Malone JM, Racy J, Leal JM, Poole J. Pschological adaptation to amputation: an overview. Orthot Prosthet 1984;38:46-50

5 Friedman LW. The Psychological Rehabilitation of the Amputee. Springfield, IL: Charles Thomas; 1978

6 Singhal S, Chand P, Singh SV, Tripathi S. Modifications to simplify fabrication of finger prosthesis: a case series. J Prosthet Orthot 2011;23:30-33

7 Sitek AJ, Yamaguchi GT, Herring DE, Willems CJ, Bininger D, Boninger RM. Development of an inexpensive upper extremity prosthesis for use in developing countries. J Prosthet Orthot 2004;16:94-102 